\title{
The prevalence of terraced treescapes in analyses of phylogenetic data sets
}

\author{
Barbara H. Dobrin*, Derrick J. Zwickl and Michael J. Sanderson
}

\begin{abstract}
Background: The pattern of data availability in a phylogenetic data set may lead to the formation of terraces, collections of equally optimal trees. Terraces can arise in tree space if trees are scored with parsimony or with partitioned, edge-unlinked maximum likelihood. Theory predicts that terraces can be large, but their prevalence in contemporary data sets has never been surveyed. We selected 26 data sets and phylogenetic trees reported in recent literature and investigated the terraces to which the trees would belong, under a common set of inference assumptions. We examined terrace size as a function of the sampling properties of the data sets, including taxon coverage density (the proportion of taxon-by-gene positions with any data present) and a measure of gene sampling "sufficiency". We evaluated each data set in relation to the theoretical minimum gene sampling depth needed to reduce terrace size to a single tree, and explored the impact of the terraces found in replicate trees in bootstrap methods.

Results: Terraces were identified in nearly all data sets with taxon coverage densities $<0.90$. They were not found, however, in high-coverage-density (i.e., $\geq 0.94$ ) transcriptomic and genomic data sets. The terraces could be very large, and size varied inversely with taxon coverage density and with gene sampling sufficiency. Few data sets achieved a theoretical minimum gene sampling depth needed to reduce terrace size to a single tree. Terraces found during bootstrap resampling reduced overall support.

Conclusions: If certain inference assumptions apply, trees estimated from empirical data sets often belong to large terraces of equally optimal trees. Terrace size correlates to data set sampling properties. Data sets seldom include enough genes to reduce terrace size to one tree. When bootstrap replicate trees lie on a terrace, statistical support for phylogenetic hypotheses may be reduced. Although some of the published analyses surveyed were conducted with edge-linked inference models (which do not induce terraces), unlinked models have been used and advocated. The present study describes the potential impact of that inference assumption on phylogenetic inference in the context of the kinds of multigene data sets now widely assembled for large-scale tree construction.
\end{abstract}

Keywords: Terrace, Partitioned model, Data decisiveness, Phylogenetics, Supermatrix, Large phylogenetic trees

\section{Background}

Among the methodological challenges in phylogenetic inference are those posed by missing data. Problems tied to incomplete data sets first emerged in the context of paleontological data matrices [1-3], from which character states may be missing because of inapplicable characters or fossil incompleteness, leading to parsimony reconstruction (used widely for morphological data sets) recovering multiple, equally good trees. A large literature (e.g., [4-16]) has since assessed the risks and identified advantages linked

* Correspondence: dobrinb@email.arizona.edu

Department of Ecology and Evolutionary Biology, University of Arizona, 1041 E. Lowell St, Tucson, AZ 85721, USA

(c) The Author(s). 2018 Open Access This article is distributed under the terms of the Creative Commons Attribution 4.0 International License (http://creativecommons.org/licenses/by/4.0/), which permits unrestricted use, distribution, and reproduction in any medium, provided you give appropriate credit to the original author(s) and the source, provide a link to the Creative Commons license, and indicate if changes were made. The Creative Commons Public Domain Dedication waiver (http://creativecommons.org/publicdomain/zero/1.0/) applies to the data made available in this article, unless otherwise stated. 
Adding to these difficulties are terraces [26, 27], collections of equally optimal trees that may arise in tree space because of the taxon coverage patterns (the pattern of gene presence/absence across taxa) in partitioned alignments, such as commonly are found in multigene data matrices. Terraces can slow tree search $[26,28]$ and mislead heuristic search algorithm [27]; when a tree search algorithm returns one putatively optimal tree that is actually on a terrace, then this adds ambiguity to tree inference. The presence of terraces can also confound confidence assessment: in bootstrapping (under some conditions), replicates are more likely to return a spurious clade if the clade occurs frequently on a terrace of optimal trees; and in Bayesian assessment, long-branch bias in the presence of missing data can elevate posterior probabilities of some of the trees belonging to a terrace [27]. The latter "phantom" support phenomenon resembles the "star paradox" [29] and Bayesian long-branch repulsion effects [30] observed elsewhere.

Precise necessary and sufficient conditions for the occurrence of terraces have been described elsewhere [26, 27]. Roughly speaking they include: 1 ) the tree optimality criterion is parsimony or partitioned maximum likelihood (ML) and, if the latter, edge lengths are optimized independently across data partitions (i.e., the inference model is "edge-unlinked" (EUL)) [27]; and 2) each partition is sampled for fewer than the full complement of taxa. For any "parent" tree, $T$, having all the taxa in a data matrix, each partition of the matrix with fewer than this number of taxa sampled induces ("displays") a subtree of $T$ with those "missing" taxa pruned. Depending on the taxon coverage pattern, these subtrees may be compatible not only with $T$ but with an assortment of other parent trees, each displaying the induced subtree (Fig. 1). If the optimality function is one of those cited above, scores of all parent trees will be identical $[26,27]$, and collectively the parent trees are called a terrace. Because terraces consist of parent trees that display the same compatible subtrees, they can be characterized using algorithms from the supertree literature; in particular, terraces can be discovered and described without the need to search tree space once the first tree, $T$, is found [26, 27].

All else being equal, terraces should arise more often from data sets with sparser taxon coverage, and more often when data span many taxa and few genes (as in a "tall" matrix), than the converse (as in a "wide" matrix) [31]. The increased prevalence of next-generation sequencing (NGS) sampling approaches will reduce the incompleteness of data matrices, but "gappiness" currently characterizes much large-scale phylogenetic data, for reasons including 1) the use of public sequence archives, which store disparate data sets composed of different taxa and different numbers of taxa; 2) biological [30] or methodological [32] barriers to obtaining orthologous sequences; 3) the use of shallow coverage protocols with NGS methods; and 4) loss of genes. In this paper, we investigate the terraces that would arise from 26 large data sets under the necessary inference assumptions. In particular, we investigated whether the published optimal trees - generally maximum likelihood trees - were on a

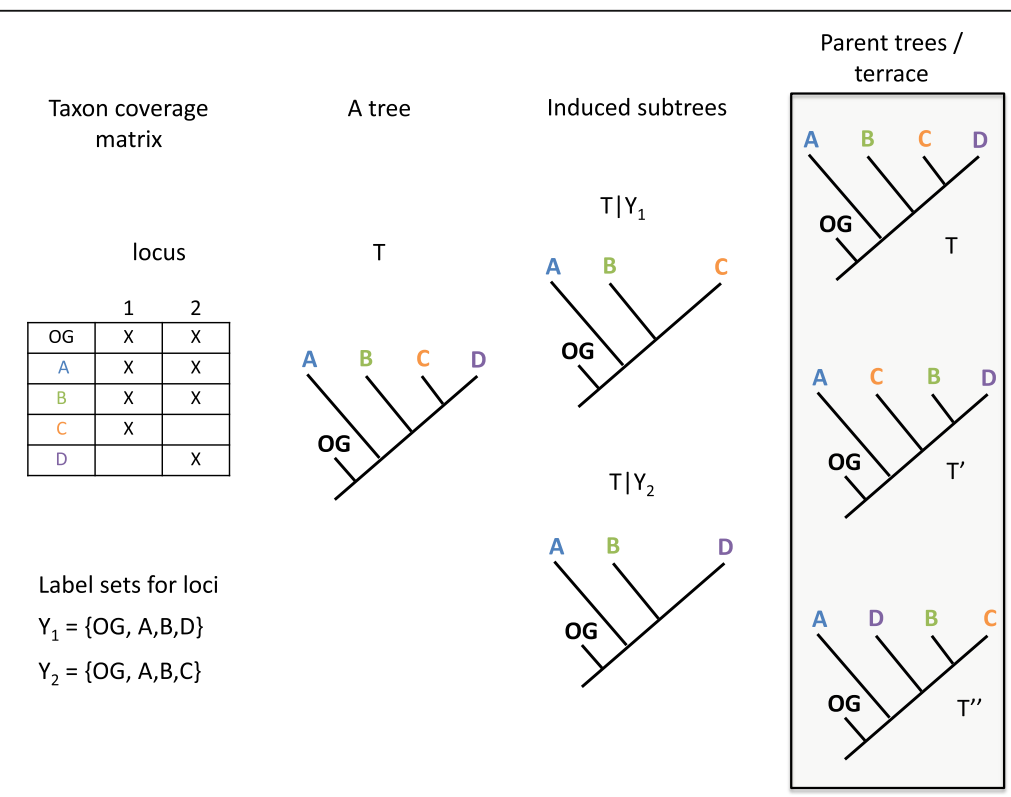

Fig. 1 Origin of terraces. The two-locus taxon coverage pattern (displayed as a taxon coverage matrix, left) of a data alignment induces two subtrees, $T \mid Y_{1}$ and $T \mid Y_{2}$, of a tree, $T$, inferred from the data. Three trees, $T, T^{\prime}$, and $T^{\prime \prime}$ all display and are parent trees of $T \mid Y_{1}$ and $T \mid Y_{2}$. If the tree scoring function is parsimony or ML-EUL, the scores of $T, T^{\prime}$, and $T^{\prime \prime}$ are identical, and the trees constitute a terrace. Figure adapted from [27]. Credit: J. Charboneau 
terrace, and the properties of those terraces. When we reviewed the methods and models used originally to recover the trees, we found surprising variability: one author [33] conducted unpartitioned analysis, another [34] reported having used an edge-linked (EL) model, and many authors left inference model details unspecified. Of those in the latter category, some may have used linked edgelength parameters (and consequently EL models), often the default parameter setting of tree reconstruction programs. However, we were less interested in evaluating the findings of the published studies than in constructing a test bed of data sets for examining the size and diversity of terraces that would emerge under EUL inference (or parsimony). EUL models have been used in likelihood-based tree reconstruction, and may confer advantages in analysis of some time-heterogeneous data sets (see Discussion); and terraces are predicted to emerge from incompletelysampled data under EUL assumptions. Accordingly, we evaluated the terraces that would have arisen if the reported trees had been products of EUL maximum likelihood inference (ML-EUL) or parsimony. We characterized the terraces, measuring their size and the diversity of their trees. We examined terrace properties in relation to the data availability characteristics of the data sets, including taxon coverage density and a measure of data sampling sufficiency derived from theory. When bootstrapping to obtain tree support values, each replicate tree may belong to a terrace. We used consensus methods to measure the impact of these terraces on bootstrap support. Finally, we examined terrace size as a function of a simple measure of overall data coverage, the percentage of taxon triples sampled within partitions. Because terrace formation in likelihood inference occurs with the use of EUL models, we also used the Akaike Information Criterion (AIC) [35] to identify the more suitable model (EL or EUL) for each data set in the study sample.

\section{Methods}

\section{Concepts and definitions}

Earlier articles [26, 27] provide detailed exposition of terraces and their properties. Here, we outline terrace theory in brief.

\section{Terraces and inference models}

Consider a data matrix consisting of aligned, homologous sites (these may be nucleotides or other characters) and $n$ taxa, with the sites subdivided into $k$ loci. We may denote the set of $n$ taxon labels as $X$. Each locus corresponds to a unit such as a gene or a codon position, or perhaps to a collection of sites demarcated by some a posteriori criterion. Throughout this article, we will refer to loci variously as "loci," "partitions," and "genes," without regard to the scheme used to cluster the data. If any data are present for a taxon at a locus, we consider that locus sampled for the taxon. The coverage pattern $S$ for the data and partitioning scheme consists of the subsets of taxa $Y_{1}, \ldots, Y_{\mathrm{k}}$ sampled for each of the $k$ loci. Taxon coverage density, or just coverage density, refers to the percentage of taxon-by-locus combinations that have any data present. We also speak of a taxon coverage matrix, which differs from the coverage pattern only in that it records the presence and absence of samples at taxon-by-locus locations.

Given a tree $T$ on $X$, each of the taxon subsets $Y_{\mathrm{j}}$ in $S$ induces a subtree $T \mid Y_{\mathrm{j}}$ composed only of taxon labels in $Y_{\mathrm{j}}$ that is, $T \mid Y_{\mathrm{j}}$ is the subtree of $T$ remaining after all taxa not present in $Y j$ are removed. The tree $\mathrm{T}$ displays the set of induced subtrees $T\left|Y_{1}, \ldots, T\right| Y_{\mathrm{k}}$, and is a parent tree of $T\left|Y_{1}, \ldots, T\right| Y_{\mathrm{k}}$. Fig. 1 illustrates how more than one tree may display (i.e., be a parent tree of) a set of subtrees induced by a taxon coverage pattern: the two-locus coverage pattern $Y_{1}, Y_{2}$ induces the subtrees $T\left|Y_{1}, T\right| Y_{2}$, of which $T$, $T$, and $T^{\prime \prime}$ are parent trees. If the parent trees are scored with an optimality function such as parsimony or maximum likelihood, and if all parent trees score the same, collectively the parent trees are called a terrace.

If the scoring criterion is parsimony, the set of parent trees is always a terrace [26]. If the criterion is maximum likelihood (ML), the parent trees are a terrace if edgelength parameters of the inference model are optimized independently across loci [27]. In this paper, we refer to models with such parameters as edge-unlinked (EUL). An edge-linked (EL) model has a single length parameter per edge (i.e., optimization is joint across loci). A partially edge-linked (PEL) model joins edge-length parameters across loci by one or more proportionality constants. Use of an EUL model is a sufficient condition for the emergence of terraces, while optimization with a linked model (EL or PEL) is insufficient - terraces do not arise under their assumptions. No conditions apply to the rate matrix of the model, which may be defined independently or jointly across loci [27].

As noted in the Introduction, often we could not discern rigorously the details of the inference models used in the phylogenetic studies in our sample. In particular, authors often left unspecified the linkage type (i.e., whether optimized jointly [linked] or separately [unlinked] across partitions) assigned to edge-length parameters, and some authors may have relied on inference tool default settings. In RAxML [36], the program used most often across the sample, parameters for edge length are linked by default, implementing a model (EL) that does not induce terraces. The authors of one analysis [34] explicitly reported having used an EL model. As we have noted, we were more interested in the impact of the structure of the data than the particular inference assumptions of the published papers, and accordingly, we investigated the terraces that would have 
arisen had the reported trees been recovered with parsimony or with some form of ML-EUL inference model.

\section{Defining and decisiveness}

If a tree $T$ on $X$ is the only parent tree of a set of subtrees induced by a coverage pattern $S$, we say that the subtrees define $T$. Similarly, a coverage pattern $S$ is said to be decisive for $T$ if $T$ is the only parent tree of the subtrees induced by $S$. Theory [31, 37] establishes necessary and sufficient conditions under which a coverage pattern achieves decisiveness. A theory of defining sets out conditions under which a set of subtrees define a tree. Here we summarize a selection of these theoretical results, described previously in [31]:

- For a coverage pattern $S$ to be decisive for all (unrooted) trees on $X$, it is sufficient that one locus is fully sampled (i.e., for every label in $X$ ). This condition follows trivially from a condition (which we do not describe here) applying to the distribution of taxon quadruples among label subsets in $S$.

- For a coverage pattern $S$ to be decisive for all (unrooted) trees on $X$, it is necessary that every triple of taxa (set of 3 taxa) is present (i.e., sampled or observed) in at least one of the taxon subsets in $S$.

The latter result suggests intuitively that the distribution of triples in a coverage pattern, and the number of parent trees that can be constructed from its induced subtrees, may be empirically correlated. Sanderson et al. 2010 [31] speculated that the percentage of observed taxon triples might indeed predict the impact of a given quantity of missing data. Further theory developed in $[31,38]$ similarly suggests such a relationship. We state here one such further result, given in [38]:

- Given a rooted tree $T$ and a coverage pattern $S$, the set of induced subtrees $T\left|Y_{1}, \ldots, T\right| Y_{\mathrm{k}}$ defines $T$ if every edge of $T$ is distinguished by some rooted triplet from $T\left|Y_{1}, \ldots, T\right| Y_{\mathrm{k}}$. To describe the concept of distinguishing informally, let $\pi$ be a leaf taxon whose incident edge subtends the root of $T$, but which is not found in $X$ (i.e., the label set of $T$ ); let $a, b$, and $c$ be taxa belonging to $X$. The rooted triplet $a \mid b c$ distinguishes an edge $e$ of $T$ if each taxon in the set $\{\pi, a, b, c\}$ has one label found in each subtree in $T$ whose roots are adjacent to $e$, and $e$ corresponds to the edge of the resolved quartet $\pi a \mid b c$.

Whether a taxon triple is associated with a distinguishing triplet depends on the shape of $T$, but taxon triple percentage can be thought of as a (numerically smaller) proxy for the proportion of edges of $T$ distinguished by rooted triplets. Edges not fixed by induced subtrees can be broken and their subtended partial trees placed elsewhere, forming equally optimal alternative topologies.

\section{Terrace discovery and analysis Selection and preparation of empirical data sets}

From recent phylogenetics literature, we selected 13 multi-locus data sets, each consisting of at least 7 loci and at least 95 taxa [33, 34, 39-48]. From the largest of these, the $\sim 33,000$-taxa vascular plant "megamatrix" of Zanne et al. [42], we extracted 13 disjoint data subsets, each corresponding to a named genus or family, and each including (with one exception) at least 95 taxa. Some of these data subsets contained fewer than the 7 loci present in the megamatrix. Across all data sets (including vascular plant subsets), the number of taxa ranged from 57 to 7000, the number of loci from 5 to 1122, and the number of aligned sites from 5054 to 504,850 . Taxon coverage densities ranged from 0.06 to 0.98 (Table 1). Of the studies selected, all but two reported maximum likelihood trees. We explored the terraces (if present) associated with these trees, characterizing terraces as they would have arisen had the published trees been products of parsimony or ML-EUL. To analyze the data set of [44], we used the published maximum clade credibility (MCC) Bayesian tree. To analyze the data set of [34], we used the published partitioning scheme and a tree that we constructed ourselves from the aligned data using parsimony heuristic search in PAUP [49]. [34] reported a tree estimated from the data (with an edge-linked (EL) model), but no machine-readable copy of the tree accompanied the article. For each data subsample of the plant megamatrix, we extracted the corresponding subtree from the $\sim 33,000$-taxa megaphylogeny. Polytomies were absent from all trees except that reported by [33].

Several of the published data alignments included sequences for taxa not found in the accompanying trees. We deleted these taxa; consequently, some taxon counts in our experimental data sets differ from the published counts. We also deleted a small number of additional taxa (three or fewer across all data sets) when we encountered difficulties processing their sequence data into the format required for terrace analysis. All final data alignments, partitioning schemes, and trees analyzed for this study have been posted on the GitHub website.

\section{Discovering and characterizing terraces}

We used the Python program 'terraphy' [50], written by DJZ, to discover and characterize the terraces. Terraphy accepts as input a data matrix of aligned sites, a partition scheme, and a tree. It computes the taxon coverage matrix for the alignment and partitioning scheme, the size of the terrace to which the tree belongs, and the strict and Adams (BUILD) [51] consensus trees of the trees on the terrace. To compute terrace size, terraphy 
Table 1 Data set profiles and results of terrace and decisiveness analyses

\begin{tabular}{|c|c|c|c|c|c|c|c|c|}
\hline Taxon & $\begin{array}{l}\text { Number } \\
\text { of taxa }\end{array}$ & $\begin{array}{l}\text { Number } \\
\text { of loci }\end{array}$ & $\begin{array}{l}\text { Number } \\
\text { of sites^ }\end{array}$ & $\begin{array}{l}\text { Taxon coverage } \\
\text { density }\end{array}$ & Terrace size & $\begin{array}{l}\rho \text { (resolution) of strict } \\
\text { consensus of trees } \\
\text { on terrace }\end{array}$ & $\begin{array}{l}\text { Min. loci needed for } \\
\text { decisiveness (kmin), } \\
p=.05\end{array}$ & $\begin{array}{l}\text { Gene (locus) } \\
\text { sampling } \\
\text { sufficiency (ठ) }\end{array}$ \\
\hline Birds & 7000 & 32 & 39,611 & 0.12 & $1.30 E+388$ & $* *$ & 129,035 & -8.3 \\
\hline Lichenized fungi & 1317 & 9 & 7433 & 0.44 & 11,655 & $* *$ & 574 & -4.16 \\
\hline Saxifragales & 946 & 51 & 48,242 & 0.06 & $* *$ & NA & $2,107,107$ & -10.63 \\
\hline Bats & 815 & 29 & 20,364 & 0.15 & $1.43 \mathrm{E}+41$ & 0.78 & 44,209 & -7.33 \\
\hline Rosaceae* & 529 & 7 & 11,728 & 0.3 & $1.72 E+23$ & 0.77 & 2627 & -5.93 \\
\hline Primates & 372 & 79 & 61,198 & 0.37 & 70.8 million & 0.92 & 982 & -2.52 \\
\hline Caryophyllaceae* & 225 & 7 & 11,753 & 0.29 & 718.3 billion & 0.77 & 2349 & -5.82 \\
\hline Scincid lizards & 213 & 6 & 5283 & 0.78 & 3 & $\sim 1.00$ & 37 & -1.83 \\
\hline Chameleons & 202 & 6 & 5054 & 0.92 & 1 & 1 & 14 & -0.83 \\
\hline Solanum* & 187 & 7 & 11,875 & 0.31 & 211.9 million & 0.68 & 1730 & -5.51 \\
\hline Primula* & 185 & 6 & 9408 & 0.43 & 2835 & 0.92 & 466 & -4.35 \\
\hline Ranunculus* & 170 & 7 & 9504 & 0.31 & 3 & 0.99 & 1889 & -5.6 \\
\hline Mammals & 169 & 26 & 35,600 & 0.94 & 1 & 1 & 11 & 0.86 \\
\hline Insects & 144 & 479 & 413,459 & 0.95 & 1 & 1 & 10 & 3.88 \\
\hline Iris* & 137 & 6 & 8098 & 0.33 & 1 & 1 & 1384 & -5.44 \\
\hline Eucalyptus* & 136 & 6 & 7512 & 0.23 & 27 & 0.9 & 5416 & -6.81 \\
\hline Asplenium* & 133 & 6 & 9797 & 0.21 & 95 & 0.64 & 8269 & -7.23 \\
\hline Euphorbia* & 131 & 7 & 11,648 & 0.28 & 759 & 0.87 & 2681 & -5.95 \\
\hline Rhododendron* & 117 & 7 & 9536 & 0.35 & 81 & 0.95 & 1034 & -5 \\
\hline Ficus* & 112 & 5 & 5645 & 0.36 & 851,445 & 0.8 & 12,357 & -7.81 \\
\hline Syzygium* & 106 & 5 & 5775 & 0.35 & 45 & 0.96 & 994 & -5.29 \\
\hline 1000 Plants. 1 & 102 & 8 & 290,719 & 0.97 & 1 & 1 & 7 & 0.15 \\
\hline 1000 Plants.2 & 102 & 620 & 290,719 & 0.91 & 1 & 1 & 13 & 3.88 \\
\hline Caryophyllales.1 & 95 & 209 & 87,082 & 0.98 & 1 & 0.99 & 8 & 3.23 \\
\hline Caryophyllales.2 & 95 & 1122 & 504,850 & 0.92 & 1 & 0.99 & 12 & 4.56 \\
\hline Allium* & 57 & 6 & 6938 & 0.24 & 973,215 & 0.32 & 4231 & -6.56 \\
\hline
\end{tabular}

$\wedge$ : Site counts do not include alignment columns containing no data, and may differ from counts reported in the original literature. $k_{\text {min: }}$ theoretical minimum number of loci that would need to be sampled to guarantee that a data set of a given sampling density and taxon count would be decisive for a random, unrooted tree, assuming random distribution of taxon samples. $\zeta$ : gene (locus) sampling depth "sufficiency": $k_{\min }$ normalized to the number of genes (loci) sampled and transformed for scale. $\zeta<0$ indicates insufficient sampling depth, $\zeta>=0$ sufficient sampling depth. * denotes a subsample of the Zanne et al. [42] vascular plant "megamatrix". **: tree enumeration or consensus tree construction terminated prior to program completion

uses the Constantinescu \& Sankoff [52] supertree algorithm, created to construct the full set of parent trees of a group of compatible input trees. To compute the Adams consensus tree, the program uses the BUILD algorithm of Aho [51]. To construct the strict consensus tree, the program relies on algorithms of Constantinescu \& Sankoff [52] and Steel [38]. The scaling properties of these operations have been described in $[26,27]$. The terraphy package also includes functionality to: 1) construct and output samples of trees from a given terrace, 2) determine whether two trees (found in bootstrap replicates, for example) belong to the same terrace, and 3) report the number of equally good subtree resolutions within each clade in the strict consensus tree of a terrace.
Terraphy treats input tree polytomies as "soft" or irresolvable. When the program receives a nonbinary tree, it evaluates the terraces of the alternative polytomy resolutions, and its output is the sum of tree counts from those terraces. The impact of polytomies on terrace tree counts is minimally relevant to this study because all but one of the trees we examined were binary.

\section{Variability among trees on terraces}

To describe the diversity of trees on the terraces, we constructed the strict consensus tree of each terrace and calculated its resolution, $\rho$ (defined as the ratio of the number of a tree's bipartitions to the number of bipartitions of a fully resolved (binary) tree of the same size). 


\section{Number of loci that must be sampled to ensure} decisiveness; "gene sampling sufficiency"

A probability model of random taxon sampling, described in $[31,53]$, predicts the lower bound on the number of loci, $k_{\mathrm{min}}$, that would need to be sampled to guarantee that a taxon coverage pattern, $S$, given its taxon coverage density and taxon number, $n$, would be decisive for some (random) tree constructed on the label set, $X$, of $S$ :

$$
k_{\min }=\frac{\ln \left(\left(\begin{array}{l}
n \\
3
\end{array}\right) / p\right)}{-\ln \left(1-d^{4}\right)}
$$

which approximates to

$$
k_{\min } \approx \frac{\log \frac{n^{3}}{6 p}}{-\log \left(1-d^{4}\right)}
$$

([53], Mike Steel, personal communication, 2015), where $d$ is the taxon coverage density of $S, n$ the number of taxa in $S$, and $p$ the desired confidence level. Henceforth, $k_{\min }$ stands for the approximation. To compare data sets, we used a normalized value that we call "gene sampling sufficiency" (i.e., the depth of the gene sampling), or $\zeta$ :

$$
\zeta=\ln \frac{k_{\min }}{k}
$$

where $k$ is the number of loci (partitions) sampled. If decisiveness for a random tree on $X$ is highly probable $(p<0.05)$, then $\zeta \geq 0$. Otherwise, $\zeta<0$.

\section{Impact of terraces on bootstrap support}

In bootstrapping, the tree returned by each bootstrap replicate may be part of a terrace of equally good trees. To examine the impact of terraces on resampling support, we selected three small-to-medium-sized (112-225 taxa) data sets whose terraces were among the larger of those recovered. From each of the three data sets, we constructed 100 RAxML rapid bootstrap trees. We used PAUP to construct a majority rule consensus tree of each bootstrap replicate set and computed $\rho$ for each majority rule consensus tree (Fig. 2). Next, using terraphy, we evaluated the terrace of each replicate tree and constructed the strict consensus tree of each terrace. Finally, we used PAUP to construct the majority rule consensus tree of each collection of strict consensus trees. We call these majority rule trees "terrace-aware," because they exclude clades present in fewer than $100 \%$ of trees on the terrace found in each bootstrap replicate. We computed $\rho$ for each "terrace-aware" consensus tree.

\section{Observed taxon triples and terrace size}

To test the conjecture of Sanderson et al. [31] that the fraction of triples sampled in taxon subsets (i.e., $\left.Y_{1}, \ldots, Y_{\mathrm{k}}\right)$ might predict the effects of a given amount of missing data, we computed the observed triple proportion (see Concepts and Definitions, earlier) for 12 data sets of relatively similar taxon coverage density and $\zeta$ values. Taxon coverage densities for this group ranged from 0.19 to 0.43 , and $\zeta$ values ranged from -4.35 to -7.81 . All data sets were chosen from among the vascular plant subsamples.

\section{Edge-length model choice}

Although terraces are only known to occur with EUL models, EL may not be the best model for all data sets. We used the Akaike Information Criterion (AIC) [35] to identify the most appropriate edge-length model for each data matrix in the study sample. For each matrix, we obtained maximum likelihood scores for a tree previously inferred from the data (in each case the tree used for terrace analysis) with both models. For likelihood analyses, we used RAxML v. 8.2.11 [36], with separate HKY85 [54] substitution matrices for each partiton of DNA data sets, and separate WAG [55] transition models for each partition of protein data sets. We used the GAMMA model of rate heterogeneity for all data sets. Within pairs of inference models, the EUL model differed from the corresponding EL model only in estimating branch lengths independently across loci. We computed $\triangle$ AIC $[56,57]$ for each pair of models.

\section{Results}

Size of terraces; relationship to taxon coverage percentage

We succeeded in measuring the terraces present in 25 data sets; the sizes ranged from one tree (a nominal terrace) to an astonishing $10^{388}$ trees (Fig. 3a, Table 1). The latter terrace was that found in the 7000-taxon data matrix, the largest (in terms of taxa) of those analyzed. In evaluating the terrace of the large (946 taxa), low-sampling-density (coverage density of .06) data set of [31], we terminated the program run after several weeks. Although the time required to count trees on this terrace implies that it is very large (as run time scales linearly with terrace size $[26,27])$, the polytomy topology $(\rho=0.82)$ of the tree may have extended the program running time (see Methods). No terrace of a data set of coverage density greater than 0.90 exceeded one tree. For the 13 plant "megamatrix" data subsets, terraces ranged in size from 1 to $\sim 10^{23}$ trees, although taxon coverage densities for these data sets spanned a narrow range, from 0.19 to 0.43 . In general, terrace size varied inversely with the taxon coverage density of the data (Fig. 3a). 


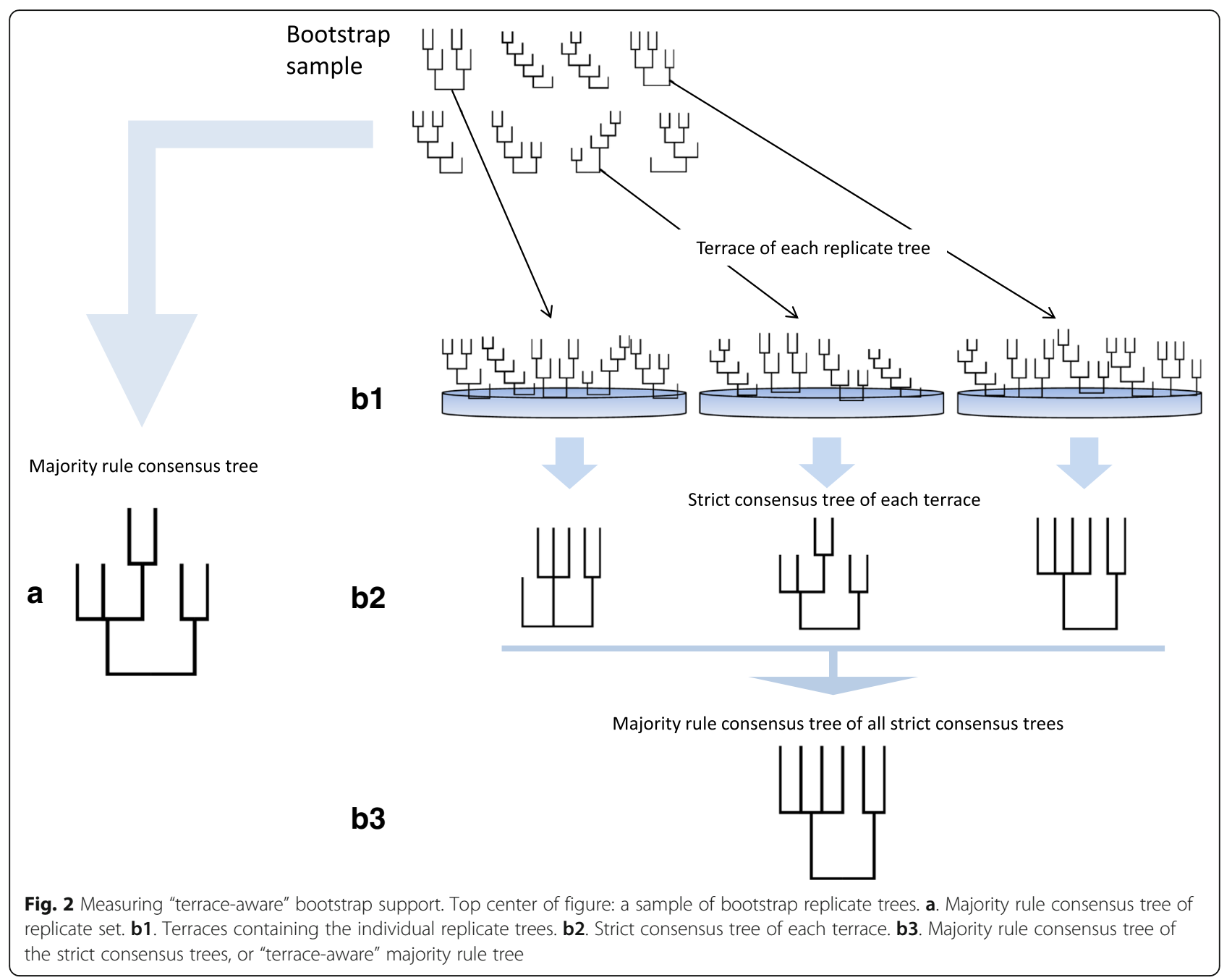

Minimum gene sampling depth needed for decisiveness $k_{\min }$ was often very large, exceeding 1000 loci for 16 data sets, and exceeding 2 million loci for one data set (Table 1). Sampling sufficiency, $\zeta$, measured less than zero (i.e., insufficient) for all but six data sets (Fig. 4a, Table 1). As with taxon coverage density, terrace size generally varied inversely with sampling sufficiency $(\zeta)$ (Fig. 4b). Terraces found in two data sets for which values of $\zeta$ were low $(-5.44$ and -5.60) comprised 1 and 3 trees, respectively, results at odds with the predictions of the Steel [53] and Sanderson et al. [31] probability model. The uniform taxon sampling assumed by their model, however, may not reflect samples found in many empirical data sets.

\section{Variability among trees on terraces}

After several weeks we terminated construction of the strict consensus tree of both the 11,655-tree terrace associated with the data set of [40], and the enormous $10^{388}$ tree terrace found in the data set of [39].
Although time to compute the strict consensus tree of a terrace scales polynomially, the large sizes of the tree (1337 taxa) on the one hand, and the terrace on the other, likely explain the long run times required to complete the program runs. For the remaining terraces, except those of one tree (nominal terraces) and the terrace discovered from the smallest data set, $\rho$ of the strict consensus trees ranged from 0.64 to 0 . 98 (Fig. 4c, Table 1). In general, $\rho$ varied inversely with terrace size (Fig. 4b); exceptions included the value $\rho=0.92$ for the $\sim 71$ million-tree terrace associated with the data set of [43]. $\rho$ measured less than 0.50 only for the consensus tree associated with the smallest data set, a 57-taxon subsample of the Zanne et al. 2014 [42] matrix.

\section{Impact of terraces on bootstrap support}

The resolution, $\rho$, of the bootstrap majority rule consensus trees measured $0.47,0.49$, and 0.56 , while $\rho$ 


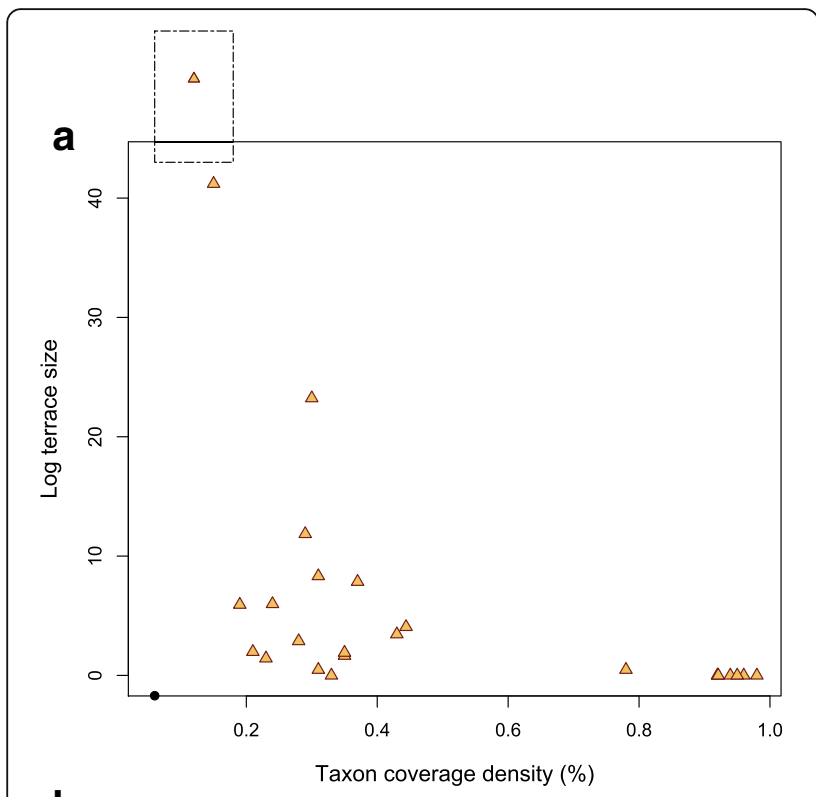

b

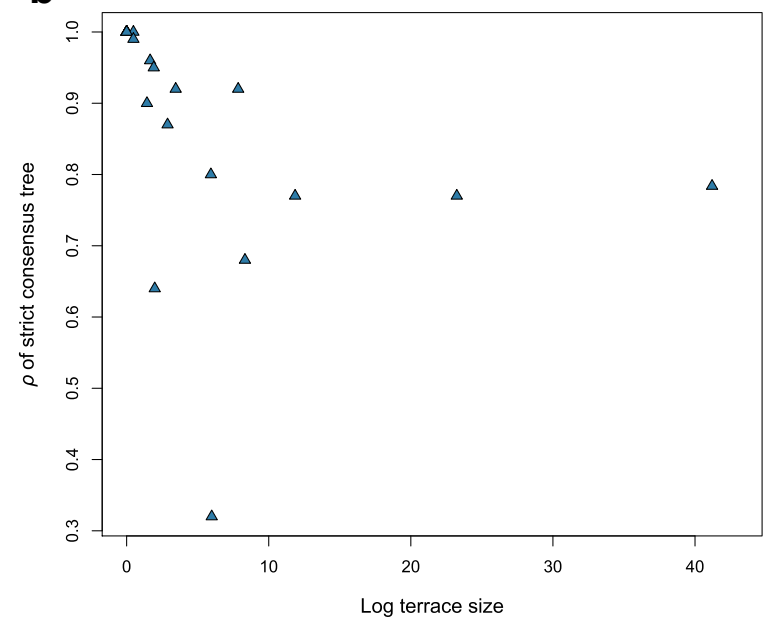

Fig. 3 Terrace properties. a: Terrace size as a function of taxon coverage density. The black dot marks the coverage density of the data set for which we terminated terrace tree enumeration before completion (see text). The data point above the plot (in dashed box) represents the largest terrace measured, $10^{388}$ trees. b: Resolution ( $\rho$ ) of the strict consensus tree of a terrace plotted as a function of terrace size. $\rho$ is defined as the ratio of the number of a tree's bipartitions to the number found in a binary tree of the same size. For two terraces identified in data sets, including the largest $\left(10^{388}\right.$ trees) and a terrace consisting of 11,655 trees, we terminated construction of the strict consensus tree before completion

for the "terrace-aware" majority-rule trees measured $0.33,0.41$, and 0.36 , respectively (Fig. 5).

\section{Percentage of taxon triples observed and terrace size}

As anticipated [31], the percentage of triples sampled within taxon subsets $\left(Y_{1}, \ldots, Y_{\mathrm{k}}\right)$ varied inversely $(p=.008)$ with terrace size among data sets of similar sampling density and $\zeta$ (Fig. 6).

\section{Edge-length model choice}

The AIC criterion favored the EUL model over the corresponding EL model for 9 data sets (Table 2), including phylogenomic and high-coverage-density data matrices from which terrace analysis recovered terraces of one tree. The EL model was preferred for the remaining data sets, including all but one of the 13 vascular plant subsets.

\section{Discussion}

The results of this analysis show that the phylogenetic trees inferred from empirical data sets often are found on large terraces of equally optimal trees, given certain assumptions about inference. The size of these terraces correlates inversely with data availability characteristics of the data: taxon sampling density, and a gene sampling "sufficiency" metric derived from theory. Evaluated by the latter measure, which incorporates the assumptions that no additional taxon sampling occurs and that sampling density does not increase, data sets seldom include enough genes to reduce terrace size to a single tree. We found that bootstrap support is reduced when the trees on terraces are included in replicate samples, and we showed how the distribution of taxon samples influences the size of terraces among data sets of otherwise similar sampling properties.

Our findings illustrate the frequency and scale at which terraces could arise from data sets assembled under a range of strategies. Of five high-coverage-density, genome- or transcriptome-scale data sets in our study sample (i.e., [34, $47,48])$ none induced terraces having more than one tree. Among low-density data sets extracted from the vascular plant megamatrix, terrace sizes varied widely; results from our taxon triple experiment show that distributions of samples across data partitions explain some of these differences. The findings for this group indicate the scale at which sets of equally optimal subtree topologies might emerge within the lower taxonomic ranks of trees inferred from extremely large ("mega"-scale) data sets. Our sample also included studies conducted at the ordinal or infra-class level (e.g., $[33,39,41,43])$, some including large species samples to provide statistical power for downstream comparative analyses. Studies in this category rely on gene-rich, low-density data gathered predominantly from public repositories, but the gene samples, though large, do not achieve the depth required to reduce terrace size to one tree.

Tests [58] of the RAxML rapid and standard bootstrap search algorithms using empirical data have shown that, although the differences are small, rapid (heuristic) bootstrap search typically returns higher support values than standard bootstrap search; and when compared for the same data set, the total number of distinct bi-partitions in standard bootstrap samples is higher than that found in rapid bootstrap samples. The likely cause of these somewhat surprising differences in support levels is that the use of non-independent starting trees in rapid search 


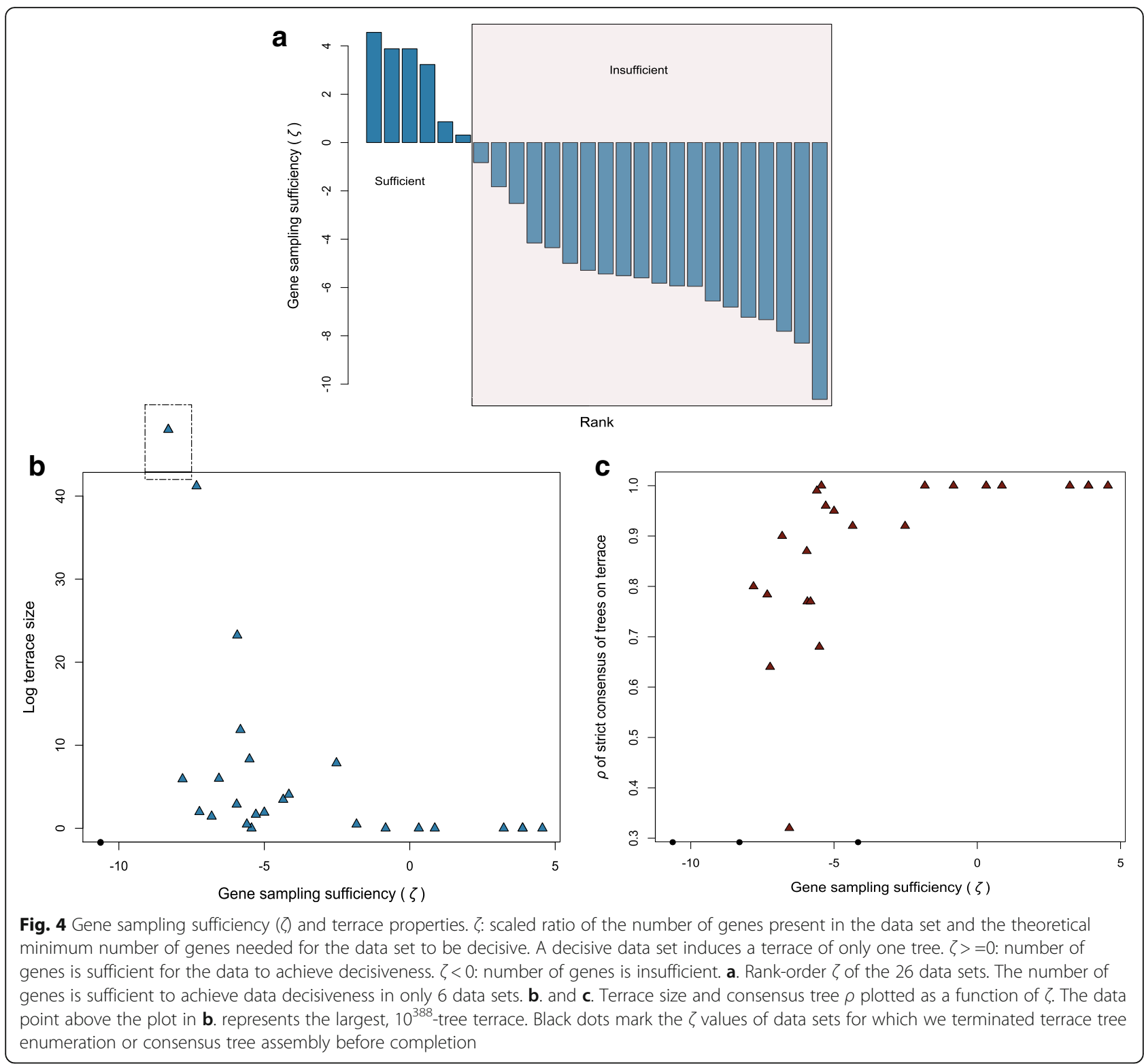

"localizes" search in tree space and leads to stronger support [58]. These findings imply that, in tree space with terraces, standard bootstrap would overstate support less than does rapid bootstrap (i.e., values of $\rho$ measured for basic and "terrace-aware" consensus trees would be nearer to one another). The effectiveness of search algorithm alternatives at estimating support in terraced tree space deserves further study.

A common approach to assembling data for the reconstruction of large and species-rich clades is to combine two data matrices of different coverage densities: a completely sampled matrix of many slow-evolving genes for a small set of taxa sharing most recent ancestors at deep nodes, and a sparser matrix of fast-evolving genes sampled for a larger collection of species concentrated in lower subclades (i.e., "top-down, bottom-up" sampling method [14, 34, 43, 46, 59]). Experiments using empirical data [14] show that this data sampling facilitates the accurate reconstruction of large clades at deep and shallow levels. Our taxon triple results suggest that terraces might arise from this sampling design if inclusion of the sparse complement - the fast-evolving genes - increases the number of taxon triples (relative to the base matrix) faster than the number of triples sampled within partition subsets. Similarly, combining incomplete taxa (taxa sampled for less than the full complement of genes) with a densely-sampled matrix of slow-evolving loci is thought to be advantageous for reconstructing deep nodes, since the incomplete data can subdivide long, saturated branches $[6,60,61]$. With this design, if blocks of 


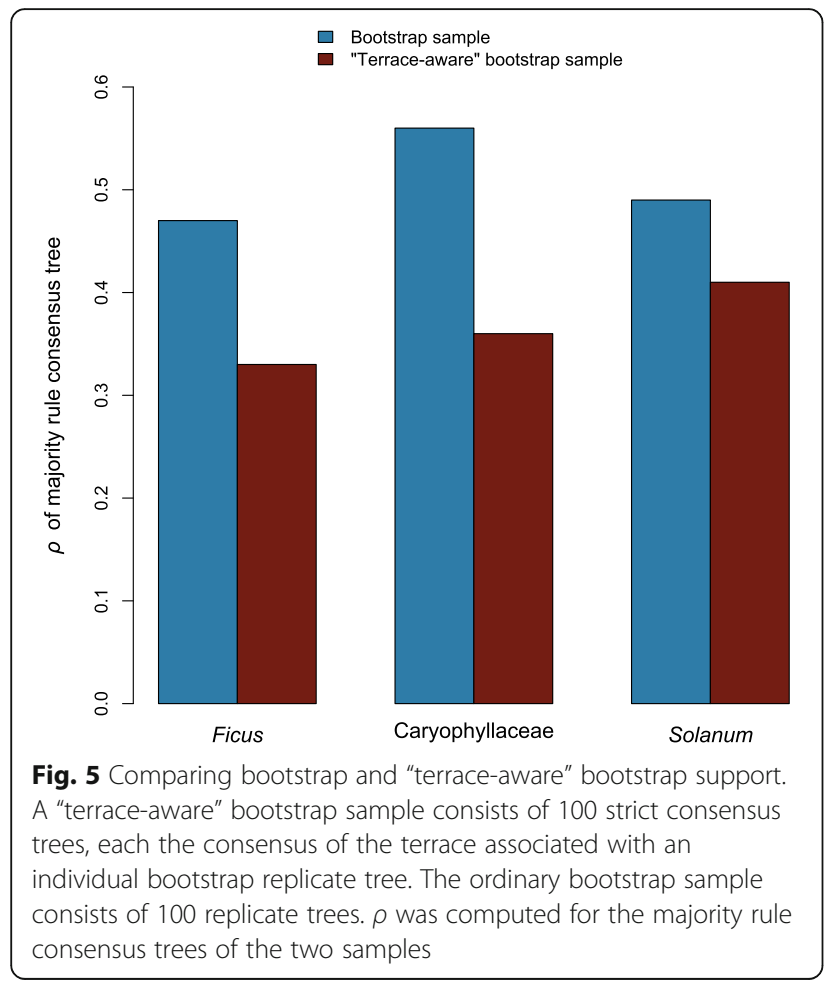

the introduced taxon labels share few sampled genes that is, if the incomplete taxa are sampled nonrandomly - we might expect terrace behaviors among the discontinuously sampled labels, as their inclusion would increase total data set taxon triples more than triples observed in partitions. Of course, in considering these common data assembly strategies, we leave aside other concerns arising from sparse or fragmented sampling (see Introduction).

Our results show that $\triangle$ AIC favored EUL models for some data sets, including many in which terrace analysis found terraces of a single tree; while favoring EL models for others, including many of lower sampling density, and most from which multi-tree terraces arose. The correlation between terraces in data sets and the information-based preference for simpler models deserves further study, but it is not unexpected, given the tendency of information-based model selection criteria to reject richer models where there are less data $[56,57]$.

\section{Inference models and "stands"}

In this paper, we described the terraces that would arise in tree inference from real data sets under parsimony or ML-EUL inference assumptions. We also noted that one or more of the trees investigated were inferred originally with EL models, which do not induce terraces. There is an important connection between several concepts here that is independent of the particular inference model. We define a stand [27] as the collection of parent trees

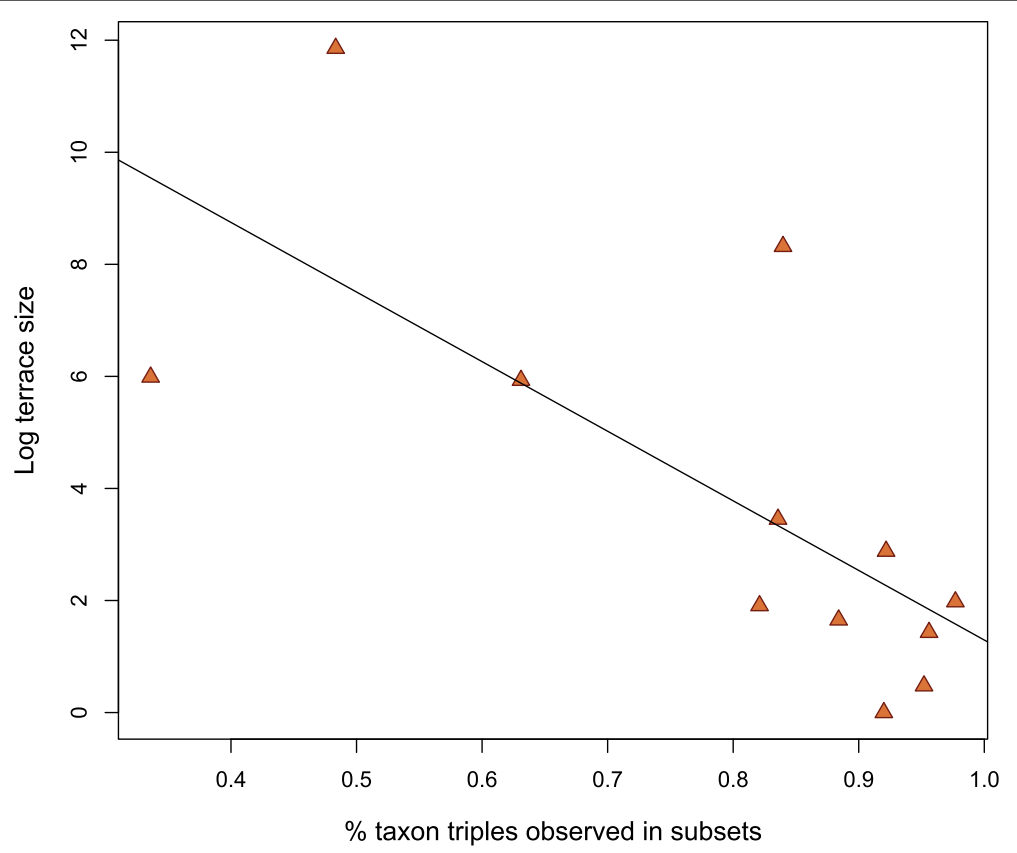

Fig. 6 Terrace size and distribution of taxon samples. Terrace size plotted against the fraction of taxon triples observed in locus subsets (see text) for 12 data sets of similar taxon coverage densities and $\zeta$. Linear regression line $p=.008$. Range of taxon coverage density values: $0.19-0.43$. Range of $\zeta$ values: $-4.35--7.81$ ( $\zeta$ : gene sampling sufficiency [see text]) 
Table 2 EL and EUL model choice

\begin{tabular}{|c|c|c|c|c|c|c|c|c|c|}
\hline Taxon & $\begin{array}{l}\text { Number } \\
\text { of taxa }\end{array}$ & $\begin{array}{l}\text { Taxon coverage } \\
\text { density }\end{array}$ & $\begin{array}{l}\text { Number } \\
\text { of loci }\end{array}$ & Model & $\begin{array}{l}\text { Number of } \\
\text { parameters }\end{array}$ & Log likelihood & $\mathrm{AIC}$ & $\begin{array}{l}\text { AIC [EL] - } \\
\text { AIC [EUL]\# }\end{array}$ & Terrace size \\
\hline \multirow[t]{2}{*}{ Insects } & 144 & 0.95 & $472 \wedge$ & $\overline{E L}$ & 757 & $-30,914,676$ & $61,830,867$ & 417,292 & 1 \\
\hline & & & & EUL & 134,992 & $-30,571,795$ & $61,413,574$ & & \\
\hline \multirow[t]{2}{*}{ Caryophyllales.2 } & 95 & 0.92 & $1120 \wedge \wedge$ & EL & 1307 & $-20,001,090$ & $40,004,795$ & 184,811 & 1 \\
\hline & & & & EUL & 210,560 & $-19,699,432$ & $39,819,984$ & & \\
\hline \multirow[t]{2}{*}{1000 Plants.2 } & 102 & 0.91 & 620 & EL & 5781 & $-8,873,326$ & $17,758,215$ & 136,442 & 1 \\
\hline & & & & EUL & 130,200 & $-8,680,687$ & $17,621,773$ & & \\
\hline \multirow[t]{2}{*}{1000 Plants.1 } & 102 & 0.97 & 8 & $\mathrm{EL}$ & 273 & $-8,881,093$ & $17,762,731$ & 43,552 & 1 \\
\hline & & & & EUL & 1680 & $-8,857,910$ & $17,719,179$ & & \\
\hline \multirow[t]{2}{*}{ Caryophyllales.1 } & 95 & 0.98 & 209 & EL & 396 & $-3,490,762$ & $6,982,316$ & 30,510 & 1 \\
\hline & & & & EUL & 39,292 & $-3,436,611$ & $6,951,806$ & & \\
\hline \multirow[t]{2}{*}{ Mammals } & 169 & 0.94 & 26 & EL & 569 & $-1,227,939$ & $2,457,016$ & 18,145 & 1 \\
\hline & & & & EUL & 8944 & $-1,210,492$ & $2,438,871$ & & \\
\hline \multirow[t]{2}{*}{ Chameleons } & 202 & 0.92 & 6 & EL & 455 & $-188,780$ & 378,471 & 4565 & 1 \\
\hline & & & & EUL & 2460 & $-184,493$ & 373,906 & & \\
\hline \multirow[t]{2}{*}{ Scincid lizards } & 213 & 0.78 & 6 & EL & 477 & $-129,669$ & 260,291 & 1410 & 3 \\
\hline & & & & EUL & 2592 & $-126,849$ & 258,881 & & \\
\hline \multirow[t]{2}{*}{ Euphorbia* } & 131 & 0.28 & 7 & EL & 322 & $-46,304$ & 93,252 & 435 & 759 \\
\hline & & & & EUL & 1876 & $-44,533$ & 92,817 & & \\
\hline \multirow[t]{2}{*}{ Iris* } & 137 & 0.33 & 6 & EL & 311 & $-29,602$ & 59,827 & -46 & 1 \\
\hline & & & & EUL & 1596 & $-28,340$ & 59,872 & & \\
\hline \multirow[t]{2}{*}{ Allium* } & 57 & 0.24 & 6 & EL & 155 & $-15,288$ & 30,886 & -217 & 973,215 \\
\hline & & & & EUL & 660 & $-14,891$ & 31,102 & & \\
\hline \multirow[t]{2}{*}{ Primula* } & 185 & 0.43 & 6 & EL & 421 & $-43,494$ & 87,831 & -801 & 466 \\
\hline & & & & EUL & 2256 & $-42,060$ & 88,631 & & \\
\hline \multirow[t]{2}{*}{ Ficus* } & 112 & 0.36 & 5 & $\mathrm{EL}$ & 264 & $-14,185$ & 28,897 & -963 & 851,445 \\
\hline & & & & EUL & 1140 & $-13,790$ & 29,860 & & \\
\hline \multirow[t]{2}{*}{ Syzygium* } & 106 & 0.35 & 5 & EL & 254 & $-14,557$ & 29,622 & -1085 & 45 \\
\hline & & & & EUL & 1090 & $-14,264$ & 30,707 & & \\
\hline \multirow[t]{2}{*}{ Solanum* } & 187 & 0.31 & 7 & $\mathrm{EL}$ & 434 & $-39,049$ & 78,967 & -1410 & 211.9 million \\
\hline & & & & EUL & 2660 & $-37,528$ & 80,376 & & \\
\hline \multirow[t]{2}{*}{ Caryophyllaceae* } & 225 & 0.29 & 7 & EL & 498 & $-67,977$ & 136,951 & -1619 & 718.3 billion \\
\hline & & & & EUL & 3108 & $-66,177$ & 138,570 & & \\
\hline \multirow[t]{2}{*}{ Asplenium* } & 133 & 0.21 & 6 & EL & 317 & $-29,688$ & 60,010 & -1758 & 8269 \\
\hline & & & & EUL & 1632 & $-29,252$ & 61,768 & & \\
\hline \multirow[t]{2}{*}{ Eucalyptus* } & 136 & 0.23 & 6 & EL & 309 & $-14,683$ & 29,984 & -1832 & 27 \\
\hline & & & & EUL & 1584 & $-14,324$ & 31,816 & & \\
\hline \multirow[t]{2}{*}{ Ranunculus* } & 170 & 0.31 & 7 & $\mathrm{EL}$ & 400 & $-32,738$ & 66,276 & -1986 & 1 \\
\hline & & & & EUL & 2422 & $-31,709$ & 68,262 & & \\
\hline \multirow[t]{2}{*}{ Rhododendron* } & 117 & 0.35 & 7 & EL & 294 & $-22,049$ & 44,687 & -2025 & 1034 \\
\hline & & & & EUL & 1680 & $-21,676$ & 46,712 & & \\
\hline \multirow[t]{2}{*}{ Rosaceae* } & 529 & 0.30 & 7 & EL & 1118 & $-83,932$ & 170,101 & -6350 & $1.72 E+23$ \\
\hline & & & & EUL & 7448 & $-80,777$ & 176,451 & & \\
\hline Lichenized fungi & 1317 & 0.44 & 9 & EL & 2712 & $-499,157$ & $1,003,737$ & -8260 & 11,655 \\
\hline
\end{tabular}


Table 2 EL and EUL model choice (Continued)

\begin{tabular}{|c|c|c|c|c|c|c|c|c|c|}
\hline Taxon & $\begin{array}{l}\text { Number } \\
\text { of taxa }\end{array}$ & $\begin{array}{l}\text { Taxon coverage } \\
\text { density }\end{array}$ & $\begin{array}{l}\text { Number } \\
\text { of loci }\end{array}$ & Model & $\begin{array}{l}\text { Number of } \\
\text { parameters }\end{array}$ & Log likelihood & $\mathrm{AIC}$ & $\begin{array}{l}\text { AIC [EL] - } \\
\text { AIC [EUL]\# }\end{array}$ & Terrace size \\
\hline & & & & EUL & 23,760 & $-482,238$ & $1,011,997$ & & \\
\hline \multirow[t]{2}{*}{ Primates } & 372 & 0.37 & 79 & EL & 1452 & $-648,012$ & $1,298,927$ & $-41,745$ & 70.8 million \\
\hline & & & & EUL & 59,250 & $-611,086$ & $1,340,672$ & & \\
\hline \multirow[t]{2}{*}{ Bats } & 815 & 0.15 & 29 & EL & 1888 & $-589,602$ & $1,182,979$ & $-51,491$ & $1.43 E+41$ \\
\hline & & & & EUL & 47,444 & $-569,791$ & $1,234,470$ & & \\
\hline \multirow[t]{2}{*}{ Saxifragales } & 946 & 0.06 & 51 & EL & 2348 & $-277,272$ & 559,240 & $-171,677$ & $* *$ \\
\hline & & & & EUL & 96,798 & $-268,660$ & 730,917 & & \\
\hline \multirow[t]{2}{*}{ Birds } & 7000 & 0.12 & 32 & EL & 14,285 & $-4,181,534$ & $8,391,639$ & $-704,755$ & $1.3 \mathrm{E}+388$ \\
\hline & & & & EUL & 448,192 & $-4,100,005$ & $9,096,394$ & & \\
\hline
\end{tabular}

\#: column displays $\triangle \mathrm{AIC}$ if $\triangle \mathrm{AIC}$ favors the EUL model, and $-\triangle \mathrm{AIC}$ otherwise. $\wedge$ and $\wedge \wedge$ : the number of loci differs from that reported in Table 1 , because we discarded loci that contained fewer than the full complement of amino acids. $\wedge: 7$ loci were discarded; $\wedge \wedge: 2$ loci were discarded. * and **: see Table 1 . For methods used to compare the models, see text

of a set of compatible input trees - here the subtrees induced from the partitions. For trees inferred with parsimony or ML-EUL, all trees on a stand score the same, and all stands are terraces. For other inference models, the stands may include trees with different scores. Our study accurately characterizes the stands - their size, the variability of their member trees, their relation to decisiveness and other data properties - as they arise in a selection of empirical data sets. Stands occur in tree space because of the taxon coverage structure of a data set. Terraces form in stands because of the inference model (or inference method) decisions of analysts. We now consider briefly the matter of this inference model choice.

In practice, the default parameter settings of tree reconstruction programs may influence model use decisions. By default, RAxML [36] links edge-length parameters of partitioned models (defining an EL model), while unlinking all other parameters. In contrast, users of the maximum likelihood program IQ-Tree [62] must affirmatively choose among EL, PEL, and EUL classes of model. Users of PAML [63] can unlink all parameters, or may use any of a collection of linkage class combinations in which edge-length parameters are fixed to partial linkage [PEL]. Users of MrBayes [64] must actively unlink parameters, but can unlink all or any combination. Terraces can arise in inference with the latter two programs and can interact with program assumptions to affect outcomes: in PAML, the likelihood score calculated with an EUL model might belong to an entire collection of topologically distinct trees. Bayesian programs may infer higher posterior probabilities for some member trees of a terrace than others, for in the presence of missing data, Bayesian priors can favor the joining of long branches [27]. With PAML and MrBayes, it is unclear whether the mechanics of specifying model parameterization (described above) might incidentally "favor" some models more than others, but with RAxML, default settings may increase the frequency of EL model use. Our review of the inference methods used across our study sample suggests that if authors relied on inference program default settings, the rate of use of EL models was quite high.

\section{Are EL inference models better for partitioned phylogenetic analyses?}

The AIC model selection criterion favored EL models in several low-coverage data sets. Moreover, terraces have only been proven to arise under EUL models. Nonetheless, there are several reasons to think EL models are not guaranteed to provide better tree reconstruction outcomes, even for low-density data. One is that the results of EL inference are susceptible to multiple artifacts not related directly to terraces, such as those cited in the Background (e.g., affecting support, model parameter, and tree topology estimates). Second, in light of the prevalence of terraces, the "optimality" of a tree selected with EL from a poorly-differentiated likelihood surface (such as is likely to arise from low-density or lowinformation data) may be illusory, reflecting the imprecision of floating point arithmetic and stochasticity in the tree search process [36, 65]. For example, different addition orders of individual site log likelihoods can result in different summed log likelihood scores. Third, a number of studies have suggested that EL models may misspecify heterotachous evolutionary patterns. Broadly speaking, evolutionary biologists have defined heterotachy as within-site rate variation over time, but in phylogenetics, a substantial literature [66-72] has focused on heterotachous patterns in which intra-site variation can be observed as differences in branch-length patterns across loci. This "among-gene heterotachy" [73] naturally suggests the use of an inference model (a "heterotachy model" [27]) that separately parameterizes branch lengths for each data partition. Authors who have addressed the inferential problems posed by this form of 
heterotachy have often assumed that the identity of sites varying in common are not known in advance and must be inferred, and accordingly have used computationally intensive mixture models to sort sites into branch-length classifications (sets) [66-68, 70]. Models in this category, and others that optimize branch-length sets separately across partitions, have been found to recover better trees or to fit empirical or simulated data better than homogeneous (homotachous) models parameterized with single sets of branch lengths [18, 66-68, 70, 72, 73]. Several studies show that homogeneous models can become inconsistent under strong forms of between-locus heterotachy [68, 71, 74], and these findings have partly motivated efforts to formulate heterotachous models. Notably, some experimenters have inferred nonindependence between genes and branch-length sets selected optimally with mixtures [73], and others have found that separate analyses conducted on broadlydefined functional categories of sequences exhibit substantially different branch-length patterns [72]. EUL parameterization seems a natural fit for these observed patterns. We urge further empirical studies addressing whether, generally, branch lengths covary among data partitions (i.e., rate shifts occur homogeneously across partitions, as would correspond with an EL model), or whether no such covariance exists, and within-partition branch length patters may be specified better with EUL parameterization. Some of the findings depended on complete data samples, but Sanderson et al. [27], using simulations to examine the effects of missing data, showed that while an edge-linked (EL) inference model correctly inferred trees from homotachous and strongly heterotachous data under full taxon coverage, the heterotachous (but not homotachous) data pattern misled the model when data were removed to form a pattern of partial taxon coverage. These results are consistent with studies undertaken in a variety of contexts showing that phylogenetic accuracy suffers from reliance on overly simple models [6,74-78], and that missing data often worsens the effects of model misspecification [5, 6, 8, 27], at times misleading models that otherwise remain robust to violations of their assumptions. It is also the case that complex models (e.g., EUL models) may overfit the data [79-81], and this consideration motivated us to identify the edge-length model favored by the AIC model selection criterion for each data set in the study sample. The results, wherein the EUL model was preferred for higher-density data, are consistent with the expectation that richer data sets should support more complex models, but may also be indicative of differences in underlying evolutionary processes. For example, the preference for the EL model for most of the vascular plant submatrices may stem from using many of the same loci between data subsets. Similarly, evolutionary rate heterogeneity among the sampled loci may account for the choice of EUL models for genomic and transcriptomic data sets. Further study of model suitability and terrace formation may shed light on the relationship of terraces per se to the phenomenon of increased estimator variance or non-identifiability (sensu Rannala [82]) that can occur in inference with highly parameterized models. When terraces do arise, the ambiguity that they introduce into tree reconstruction can be mitigated by adding data, or can be integrated over to provide hypotheses for downstream evolutionary analysis.

\section{Remediating, summarizing, and analyzing terraces Reducing terrace size}

Given a tree $T$ on a labels set $X$, and a set of subtrees $T\left|Y_{1}, \ldots, T\right| Y_{\mathrm{k}}$ induced by a taxon coverage pattern $Y_{1}, \ldots, Y_{\mathrm{k}}$, an algorithm adapted from the supertree literature can identify the smallest set of taxon labels to remove from $\mathrm{X}$ so that the subtrees $T^{*}\left|Y_{1}, \ldots, T^{*}\right| Y_{\mathrm{k}}$ define a reduced tree, $T^{*}[26]$. Under the appropriate inference model, this stand of size one will then be a terrace of size one. This problem, of finding the maximum defining label set (MDLS), has an exact and easily computed solution for two induced subtrees (i.e., two loci). For data sets of more than two loci, applying the algorithm successively to pairs of loci gives an approximate solution $[26,27]$. Taxa outside the MDLS, or outside the intersection of pairwise MDLSs, can be sampled for all loci, or their data removed. The MDLS solutions of trees in a confidence set, however, may differ from one another and from that of the original tree. Moreover, data augmented with new samples may imply a phylogeny not defined by its induced subtrees.

\section{Fully sampling one gene}

As noted earlier, a taxon coverage pattern is always decisive if any one gene is sampled for all taxa. However, full taxon coverage for one gene does not guarantee that the likelihood (or other score) surface will be well behaved; as noted in [26], a terrace-like flatness might characterize scores inferred from decisive data, if decisiveness is achieved with low-signal data restricted to a single gene.

\section{Partitioning to reduce the size of terraces}

Sanderson et al. [27] showed that for every data set, a unique maximal partition exists and that it corresponds to a maximal terrace (the largest terrace). Parsimony analyses should report the maximal partition and terrace, since parsimony scores would be unaffected. With maximum likelihood, partitioning to maximize model fit or performance may sometimes reduce the size of terraces. A procedure developed by Li et al. [79] for finding the optimal number of parameters in an inference model can reduce the number of partitions. With incompletely 
sampled data, reducing partition number should increase taxon coverage density and could reduce terrace size. In an analysis of genome-scale data, Xi et al. [59] used Bayesian inference of model mixtures to group sites by substitution pattern. The resulting partitioning scheme improved likelihood (as measured by AIC) and reduced terrace size compared to partitioning a priori by gene and codon position.

\section{Summarizing and analyzing terraces}

In addition to functions for computing consensuses, three terraphy package tools support terrace analysis and reporting. As noted earlier, an annotating tool reports the number of equally good subtree resolutions per clade of the strict consensus tree of a terrace. This feature decomposes terrace-based ambiguity into its combinatoric elements for analysis, and helps to highlight unresolved regions of large trees. Another feature constructs and outputs random trees sampled from a given terrace, allowing investigation of the impact of terraces on downstream comparative analyses. A third feature reports whether two trees belong to the same terrace. In conjunction with data from the strict consensus tree and taxon coverage matrix, the latter functionality could be used to detect the signature of another hazard of terraces, the supported, spurious clade. An experiment conducted on simulated data [27] showed that when sampling overlap between two clades is minimal i.e., the groups share few sampled loci - the clades may be found merged in a large proportion of trees on the terrace. If many bootstrap trees fall on the terrace, the spurious clade in turn would occur at high frequency in the bootstrap sample. The data used for the experiment comprised two partitions of sequences patterned to ensure that bootstrap trees achieved identical scores, and translating the results to a prediction applicable to, for example, larger collections of loci or more complex patterns of sampling discontinuity would require further experiments. If an artifact of this type arose in real data, however, it would predict a conjunction of outcomes at a node: strong support among bootstrap replicate trees that reside on the terrace, and in the terrace consensus tree, weak resolution of the interior branches of the clade compared to a binary tree.

\section{Conclusion}

Provided certain inference assumptions apply, the phylogenetic trees recovered from many large empirical data sets belong to large terraces of equally optimal trees. The size of these terraces varies inversely with two sampling properties of the data: taxon coverage density and gene sampling "sufficiency," a measure derived from data decisiveness theory. Evaluated on this scale, which treats taxon sampling density and taxon count as fixed, data sets seldom include enough genes to reduce terrace size to one tree. At a given sampling density, a measure of the distribution of samples among genes can often predict the impact of terraces. The terraces found in bootstrap replicates can reduce resampling support for phylogenetic hypotheses. The widespread adoption of NGS approaches to data assembly will reduce incompleteness in data sets, and also the prevalence of terraces. A new program, terraphy, provides terrace discovery, analysis, and reporting tools.

The methods used originally by authors to reconstruct the published trees were variable and included inference with EL (edge-linked) models. Models of this type do not induce terraces, but for all data sets and starting trees surveyed, our findings characterize the collections (stands) of trees, many very large, as they arise from the data sets. Under EL inference, these trees have different scores. Under ML-EUL or parsimony inference assumptions, these collections of trees would be terraces. We used the AIC model choice criterion to determine the most appropriate edge-length model (EL or EUL) for each data set, and found that EUL models were preferred for some, including high-coverage data sets which induce single-tree terraces; whereas EL models were favored for others. The correspondence between singletree terraces and selection of the EUL model is in line with expectations, given that sparse data may be insufficient to support complex models and also give rise to terraces. These model choice results, and the relationship between terraces and model suitability, deserve further study. If EL models are used to analyze low-density or low-signal data sets, terrace analysis can reveal potential ambiguity in the inference, for the likelihood surface recovered under such a data-and-model combination is likely to be poorly differentiated. The present study reveals the scale and frequency at which terraces would arise from parsimony or edge-unlinked maximum likelihood analyses of large data sets, and allows us to add terraces to the list of challenges in phylogenetic analysis from sparsely sampled and large collections of data.

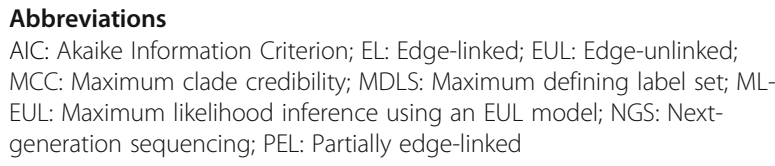

\section{Acknowledgments}

We thank the Associate Editor and reviewers Mark Simmons and Matt Phillips for their insightful comments, which greatly improved the manuscript.

\section{Funding}

This work was funded by the National Science Foundation (grant DEB-1353815 to MJS and DJZ).

\section{Availability of data and materials}

The data sets supporting the results and conclusions of this article are available on the GitHub website, http://github.com/BDobrin/data.sets 


\section{Authors' contributions}

BHD, DJZ, and MJS conceived the study and designed the analyses. DJZ wrote the analytical software. BHD conducted the analyses and wrote the paper. All authors read, revised, and approved the paper.

\section{Ethics approval and consent to participate}

Not applicable.

\section{Consent for publication}

Not applicable.

\section{Competing interests}

The authors declare that they have no competing interests.

\section{Publisher's Note}

Springer Nature remains neutral with regard to jurisdictional claims in published maps and institutional affiliations.

\section{Received: 29 July 2017 Accepted: 22 March 2018}

\section{Published online: 04 April 2018}

\section{References}

1. Wilkinson M. Coping with abundant missing entries in phylogenetic inference using parsimony. Syst Biol. 1995;44(4):501-14.

2. Donoghue MJ, Doyle JA, Gauthier J, Kluge AG, Rowe T. The importance of fossils in phylogeny reconstruction. Annu Rev Ecol Syst. 1989:20:431-60.

3. Wilkinson M, Benton MJ. Sphenodontid phylogeny and the problems of multiple trees. Philosophical Transactions of the Royal Society of London Series B-Biological Sciences. 1996;351(1335):1-16.

4. Huelsenbeck JP. When are fossils better than extant taxa in phylogenetic analysis. Syst Zool. 1991;40(4):458-69.

5. Xi Z, Liu L, Davis CC. The impact of missing data on species tree estimation. Mol Biol Evol. 2016;33(3):838-60.

6. Roure $B$, Baurain D, Philippe $H$. Impact of missing data on phylogenies inferred from empirical Phylogenomic data sets. Mol Biol Evol. 2013;30(1):197-214.

7. Hartmann S, Vision TJ. Using ESTs for phylogenomics: can one accurately infer a phylogenetic tree from a gappy alignment? BMC Evol Biol. 2008;8:95.

8. Xia X. Phylogenetic Bias in the Likelihood Method Caused by Missing Data Coupled with Among-Site Rate Variation: An Analytical Approach. In: Basu M, Pan Y, Wang J, editors. Bioinformatics Research and Applications. ISBRA 2014. Lecture Notes in Computer Science, vol. 8492, 2014. Cham: Springer. p. 12-23.

9. Lemmon AR, Brown JM, Stanger-Hall K, Lemmon EM. The effect of ambiguous data on phylogenetic estimates obtained by maximum likelihood and Bayesian inference. Syst Biol. 2009;58(1):130-45.

10. Wiens JJ, Moen DS. Missing data and the accuracy of Bayesian phylogenetics. J Syst Evol. 2008;46(3):307-14.

11. Wiens JJ, Morrill MC. Missing data in phylogenetic analysis: reconciling results from simulations and empirical data. Syst Biol. 2011;60(5):719-31.

12. Wiens JJ. Missing data and the design of phylogenetic analyses. J Biomed Inform. 2006;39(1):34-42.

13. Cho S, Zwick A, Regier JC, Mitter C, Cummings MP, Yao J, Du Z, Zhao H, Kawahara AY, Weller S, Davis DR, Baixeras J, Brown JW, Parr C. Can deliberately incomplete gene sample augmentation improve a phylogeny estimate for the advanced moths and butterflies (Hexapoda: Lepidoptera)? Syst Biol. 2011;60(6):782-96.

14. Wiens JJ, Fetzner JW, Parkinson CL, Reeder TW. Hylid frog phylogeny and sampling strategies for speciose clades. Syst Biol. 2005;54(5):719-48.

15. Jiang W, Chen S, Wang H, Li D, Wiens JJ. Should genes with missing data be excluded from phylogenetic analyses? Mol Phylogenet Evol. 2014;80:308-18.

16. Driskell AC, Ane C, Burleigh JG, McMahon MM, O'Meara BC, Sanderson MJ. Prospects for building the tree of life from large sequence databases. Science. 2004;306(5699):1172-4.

17. Wiens JJ. Missing data, incomplete taxa, and phylogenetic accuracy. Syst Biol. 2003;52(4):528-38.

18. Philippe H, Snell EA, Bapteste E, Lopez P, Holland P, Casane D. Phylogenomics of eukaryotes: impact of missing data on large alignments. Mol Biol Evol. 2004;21(9):1740-52

19. Simmons MP. Limitations of locally sampled characters in phylogenetic analyses of sparse supermatrices. Mol Phylogenet Evol. 2014;74:1-14.

20. Novacek MJ. Fossils, topologies, missing data, and the higher level phylogeny of eutherian mammals. Syst Biol. 1992;41(1):58-73.
21. Simmons MP, Goloboff PA. Dubious resolution and support from published sparse supermatrices: the importance of thorough tree searches. Mol Phylogenet Evol. 2014;78:334-48.

22. Simmons MP. Misleading results of likelihood-based phylogenetic analyses in the presence of missing data. Cladistics. 2012;28(2):208-22.

23. Goloboff PA, Pol D. Parsimony and Bayesian phylogenetics. In Parsimony, Phylogeny, and Genomics. Edited by Albert VA. Oxford; New York: Oxford University Press; 2006:148-61.

24. Simmons MP, Freudenstein JV. Spurious $99 \%$ bootstrap and jackknife support for unsupported clades. Mol Phylogenet Evol. 2011;61(1):177-91.

25. Goloboff PA, Simmons MP. Bias in tree searches and its consequences for measuring group supports. Syst Biol. 2014;63(6):851-61.

26. Sanderson MJ, McMahon MM, Steel M. Terraces in phylogenetic tree space. Science. 2011;333(6041):448-50.

27. Sanderson MJ, McMahon MM, Stamatakis A, Zwickl DJ, Steel M. Impacts of terraces on phylogenetic inference. Syst Biol. 2015;64(5):709-26.

28. Chernomor $\mathrm{O}$, Minh $\mathrm{BQ}$, von Haeseler A. Consequences of common topological rearrangements for partition trees in Phylogenomic inference. J Comput Biol. 2015;22(12):1129-42.

29. Steel M, Matsen FA. The Bayesian "star paradox" persists for long finite sequences. Mol Biol Evol. 2007;24(4):1075-9.

30. Siddall ME. Unringing a bell: metazoan phylogenomics and the partition bootstrap. Cladistics. 2010;26(4):444-52.

31. Sanderson MJ, McMahon MM, Steel M. Phylogenomics with incomplete taxon coverage: the limits to inference. BMC Evol Biol. 2010;10:155.

32. Thomson RC, Shaffer HB. Sparse Supermatrices for phylogenetic inference: taxonomy, alignment, rogue taxa, and the phylogeny of living turtles. Syst Biol. 2010;59(1):42-58.

33. Soltis DE, Mort ME, Latvis M, Mavrodiev EV, O'Meara BC, Soltis PS, Burleigh JG, Rubio de Casas R. Phylogenetic relationships and character evolution analysis of Saxifragales using a Supermatrix approach. Am J Bot. 2013;100(5):916-29.

34. Misof B, Liu S, Meusemann K, Peters RS, Donath A, Mayer C, Frandsen PB, Ware J, Flouri T, Beutel RG, Niehuis O, Petersen M, Izquierdo-Carrasco F, Wappler T, Rust J, Aberer AJ, Aspoeck U, Aspoeck H, Bartel D, Blanke A, Berger S, Boehm A, Buckley TR, Calcott B, Chen J, Friedrich F, Fukui M, Fujita M, Greve C, Grobe P, Gu S, Huang Y, Jermiin LS, Kawahara AY, Krogmann L, Kubiak M, Lanfear R, Letsch H, Li Y, Li Z, Li J, Lu H, Machida R, Mashimo Y, Kapli P, DD MK, Meng G, Nakagaki Y, Luis Navarrete-Heredia J, Ott M, Ou Y, Pass G, Podsiadlowski L, Pohl H, von Reumont BM, Schuette K, Sekiya K, Shimizu S, Slipinski A, Stamatakis A, Song W, Su X, Szucsich NU, Tan M, Tan X, Tang M, Tang J, Timelthaler G, Tomizuka S, Trautwein M, Tong X, Uchifune T, Walzl MG, Wiegmann BM, Wilbrandt J, Wipfler B, TKF W, Wu Q, Wu G, Xie Y, Yang S, Yang Q, Yeates DK, Yoshizawa K, Zhang Q, Zhang R, Zhang W, Zhang Y, Zhao J, Zhou C, Zhou L, Ziesmann T, Zou S, Li Y, Xu X, Zhang Y, Yang H, Wang J, Wang J, Kjer KM, Zhou X. THIS ONE HERE Phylogenomics resolves the timing and pattern of insect evolution. Science. 2014, 346(6210):763-7.

35. Akaike H. Information Theory and an Extension of the Maximum Likelihood Principle. In: Petrov MB, Caski F, editors. Proceedings of the Second International Symposium on Information Theory. Budapest: Akademiai Kiado; 1973. p. 267-81

36. Stamatakis A. RAxML version 8: a tool for phylogenetic analysis and postanalysis of large phylogenies. Bioinformatics. 2014;30(9):1312-3.

37. Steel M, Sanderson MJ. Characterizing phylogenetically decisive taxon coverage. Appl Math Lett. 2010;23(1):82-6.

38. Steel M. The complexity of reconstructing trees from qualitative characters and subtrees. J Classif. 1992;9(1):91-116.

39. Burleigh JG, Kimball RT, Braun EL. Building the avian tree of life using a large-scale, sparse supermatrix. Mol Phylogenet Evol. 2015;84:53-63.

40. Miadlikowska J, Kauff F, Hognabba F, Oliver JC, Molnar K, Fraker E, Gaya E, Hafellner J, Hofstetter V, Gueidan C, MAG O, Hodkinson B, Kukwa M, Luecking R, Bjoerk C, HJM S, Rosa Burgaz A, Thell A, Passo A, Myllys L, Goward T, Fernandez-Brime S, Hestmark G, Lendemer J, Lumbsch HT, Schmull M, Schoch CL, Serusiaux E, Maddison DR, Arnold AE, Lutzoni F, Stenroos S. A multigene phylogenetic synthesis for the class Lecanoromycetes (Ascomycota): 1307 fungi representing 1139 infrageneric taxa, 317 genera and 66 families. Mol Phylogenet Evol. 2014;79:132-68.

41. Shi JJ, Rabosky DL. Speciation dynamics during the global radiation of extant bats. Evolution. 2015;69(6):1528-45.

42. Zanne AE, Tank DC, Cornwell WK, Eastman JM, Smith SA, FitzJohn RG, McGlinn DJ, O'Meara BC, Moles AT, Reich PB, Royer DL, Soltis DE, Stevens 
PF, Westoby M, Wright IJ, Aarssen L, Bertin RI, Calaminus A, Govaerts R, Hemmings F, Leishman MR, Oleksyn J, Soltis PS, Swenson NG, Warman L, Beaulieu JM. Three keys to the radiation of angiosperms into freezing environments. Nature. 2014;506(7486):89-92.

43. Springer MS, Meredith RW, Gatesy J, Emerling CA, Park J, Rabosky DL, Stadler T, Steiner C, Ryder OA, Janecka JE, Fisher CA, Murphy WJ. Macroevolutionary dynamics and historical biogeography of primate diversification inferred from a species Supermatrix. PLoS One. 2012;7(11):e49521.

44. Rabosky DL, Donnellan SC, Grundler M, Lovette IJ. Analysis and visualization of complex macroevolutionary dynamics: an example from Australian Scincid lizards. Syst Biol. 2014;63(4):610-27.

45. Tolley KA, Townsend TM, Vences M. Large-scale phylogeny of chameleons suggests African origins and Eocene diversification. Proc Biol Sci. 2013; 280(1759):20130184.

46. Meredith RW, Janecka JE, Gatesy J, Ryder OA, Fisher CA, Teeling EC, Goodbla A, Eizirik E, Simao TLL, Stadler T, Rabosky DL, Honeycutt RL, Flynn JJ, Ingram CM, Steiner C, Williams TL, Robinson TJ, Burk-Herrick A, Westerman M, Ayoub NA, Springer MS, Murphy WJ. Impacts of the cretaceous terrestrial revolution and $\mathrm{KPg}$ extinction on mammal diversification. Science. 2011;334(6055):521-4.

47. Wickett NJ, Mirarab S, Nguyen N, Warnow T, Carpenter E, Matasci N, Ayyampalayam S, Barker MS, Burleigh JG, Gitzendanner MA, Ruhfel BR, Wafula E, Der JP, Graham SW, Mathews S, Melkonian M, Soltis DE, Soltis PS, Miles NW, Rothfels CJ, Pokorny L, Shaw AJ, DeGironimo L, Stevenson DW, Surek B, Villarreal JC, Roure B, Philippe H, dePamphilis CW, Chen T, Deyholos MK, Baucom RS, Kutchan TM, Augustin MM, Wang J, Zhang Y, Tian Z, Yan Z, Wu X, Sun X, Wong GK, Leebens-Mack J. Phylotranscriptomic analysis of the origin and early diversification of land plants. Proc Natl Acad Sci U S A. 2014;111(45):E4868.

48. Yang Y, Moore MJ, Brockington SF, Soltis DE, Wong GK, Carpenter EJ, Zhang Y, Chen L, Yan Z, Xie Y, Sage RF, Covshoff S, Hibberd JM, Nelson MN, Smith SA. Dissecting molecular evolution in the highly diverse plant clade Caryophyllales using transcriptome sequencing. Mol Biol Evol. 2015;32(8):2001-14.

49. Swofford DL: PAUP*. Phylogenetic Analysis Using Parsimony (*and Other Methods). Version 4 ed. Sunderland, Massachusetts: Sinauer Associates; 2002.

50. Zwickl D: Terraphy: Various analyses and utilities related to phylogenetic terraces. 2014. https://github.com/zwickl/terraphy/. Accessed July 2016.

51. Aho AV, Sagiv $Y$, Szymanski TG, Ullman JD. Inferring a tree from lowest common ancestors with an application to the optimization of relational expressions. SIAM J Comput. 1981;10(3):405-21.

52. Constantinescu M, Sankoff D. An efficient algorithm for Supertrees. J Classif. 1995;12(1):101-12.

53. Steel M. Phylogeny : Discrete and Random Processes in Evolution. Philadelphia: Society for Industrial and Applied Mathematics; 2016.

54. Hasegawa M, Kishino H, Yano TA. Dating of the human ape splitting by a molecular clock of mitochondrial-DNA. J Mol Evol. 1985;22(2):160-74.

55. Whelan S, Goldman N. A general empirical model of protein evolution derived from multiple protein families using a maximum-likelihood approach. Mol Biol Evol. 2001;18(5):691-9.

56. Burnham KP, Anderson DR. Model Selection and Inference A Practical Information-Theoretic Approach: S.I. New York: Springer; 1998.

57. Burnham KP, Anderson DR. Multimodel inference - understanding AIC and BIC in model selection. Sociol Methods Res. 2004;33(2):261-304.

58. Stamatakis A, Hoover P, Rougemont J. A rapid bootstrap algorithm for the RAxML web servers. Syst Biol. 2008;57(5):758-71.

59. Xi Z, Ruhfel BR, Schaefer $H$, Amorim AM, Sugumaran M, Wurdack K, Endress PK, Matthews ML, Stevens PF, Mathews S, Davis CC. Phylogenomics and a posteriori data partitioning resolve the cretaceous angiosperm radiation Malpighiales. Proc Natl Acad Sci U S A. 2012;109(43):17519-24.

60. Wiens JJ. Can incomplete taxa rescue phylogenetic analyses from longbranch attraction? Syst Biol. 2005;54(5):731-42.

61. Wiens JJ, Tiu J. Highly incomplete taxa can rescue phylogenetic analyses from the negative impacts of limited taxon sampling. PLoS One. 2012;7(8):e42925.

62. Nguyen L-T, Schmidt HA, von Haeseler A, Minh BQ. IQ-TREE: a fast and effective stochastic algorithm for estimating maximum-likelihood phylogenies. Mol Biol Evol. 2015;32(1):268-74.

63. Yang Z. PAML 4: phylogenetic analysis by maximum likelihood. Mol Biol Evol. 2007;24(8):1586-91.
64. Ronquist F, Teslenko M, van der Mark P, Ayres DL, Darling A, Hohna S, Larget B, Liu L, Suchard MA, Huelsenbeck JP. MrBayes 3.2: efficient Bayesian phylogenetic inference and model choice across a large model space. Syst Biol. 2012;61(3):539-42.

65. Zwickl DJ. Genetic algorithm approaches for the phylogenetic analysis of large biological sequence datasets under the maximum likelihood criterion [Thesis]: School of Biological Sciences, University of Texas at Austin; 2006.

66. Pagel M, Meade A. Modelling heterotachy in phylogenetic inference by reversible-jump Markov chain Monte Carlo. Philosophical Transactions of the Royal Society B-Biological Sciences. 2008;363(1512):3955-64.

67. Meade A, Pagel M. A Phylogenetic Mixture Model for Heterotachy. In: Pontarotti P, editor. Evolutionary Biology from Concept to Application. Berlin Heidelberg: Springer-Verlag; 2008. p. 29

68. Kolaczkowski B, Thornton JW. Performance of maximum parsimony and likelihood phylogenetics when evolution is heterogeneous. Nature. 2004; 431(7011):980-4.

69. Gaucher EA, Miyamoto MM. A call for likelihood phylogenetics even when the process of sequence evolution is heterogeneous. Mol Phylogenet Evol. 2005;37(3):928-31.

70. Kolaczkowski B, Thornton JW. A mixed branch length model of heterotachy improves phylogenetic accuracy. Mol Biol Evol. 2008;25(6):1054-66.

71. Spencer M, Susko E, Roger AJ. Likelihood, parsimony, and heterogeneous evolution. Mol Biol Evol. 2005;22(5):1161-4.

72. Rodriguez-Ezpeleta N, Philippe $\mathrm{H}$, Brinkmann $\mathrm{H}$, Becker B, Melkonian M. Phylogenetic analyses of nuclear, mitochondrial, and plastid multigene data sets support the placement of Mesostigma in the Streptophyta. Mol Biol Evol. 2007;24(3):723-31.

73. Zhou Y, Rodrigue N, Lartillot N, Philippe H. Evaluation of the models handling heterotachy in phylogenetic inference. BMC Evol Biol. 2007;7:206.

74. Philippe H, Zhou Y, Brinkmann H, Rodrigue N, Delsuc F. Heterotachy and long-branch attraction in phylogenetics. BMC Evol Biol. 2005;5:50.

75. Phillips MJ, Delsuc F, Penny D. Genome-scale phylogeny and the detection of systematic biases. Mol Biol Evol. 2004;21(7):1455-8.

76. Lartillot N. Probabilistic models of eukaryotic evolution: time for integration. Philos Trans R Soc Lond B Biol Sci. 2015;370(1678):20140338.

77. Posada D, Buckley TR. Model selection and model averaging in phylogenetics: advantages of Akaike information criterion and Bayesian approaches over likelihood ratio tests. Syst Biol. 2004;53(5):793-808.

78. Kuhner MK, Felsenstein J. A simulation comparison of phylogeny algorithms under equal and unequal evolutionary rates (Vol 11, Pg 459, 1994). Mol Biol Evol. 1995;12(3):525.

79. Li C, Lu G, Orti G. Optimal data partitioning and a test case for ray-finned fishes (Actinopterygii) based on ten nuclear loci. Syst Biol. 2008;57(4):519-39.

80. Nylander J, Ronquist F, Huelsenbeck JP, Nieves-Aldrey JL. Bayesian phylogenetic analysis of combined data. Syst Biol. 2004;53(1):47-67.

81. Sullivan J, Joyce P. Model selection in phylogenetics. Annual Review of Ecology Evolution and Systematics. 2005:36:445-66.

82. Rannala B. Identifiability of parameters in MCMC Bayesian inference of phylogeny. Syst Biol. 2002;51(5):754-60

\section{Submit your next manuscript to BioMed Central and we will help you at every step:}

- We accept pre-submission inquiries

- Our selector tool helps you to find the most relevant journal

- We provide round the clock customer support

- Convenient online submission

- Thorough peer review

- Inclusion in PubMed and all major indexing services

- Maximum visibility for your research

Submit your manuscript at www.biomedcentral.com/submit 